\title{
Saúde mental sob a ótica de Agentes Comunitários de Saúde: a percepção de quem cuida
}

\author{
Mental health in the perspective of Community Health Agents: \\ perceptions of caregivers
}

Thamiris Maria Nascimento Cabral1, Paulette Cavalcanti de Albuquerque $\mathbf{2}$

RESUMO Este estudo buscou identificar a percepção de Agentes Comunitárias de Saúde (ACS) no tocante aos problemas de saúde mental na comunidade. Intervir junto a indivíduos em sofrimento psíquico é um desafio, pois a loucura é marcada por mitos negativos, o que sugere conhecer as concepções dos profissionais envolvidos no cuidado desses sujeitos. Para a realização da coleta de dados, foi utilizada a técnica do grupo focal, seguida de análise de conteúdo. Verificou-se que, embora as intervenções no campo da saúde mental estejam sendo revistas e realizadas de maneira mais abrangente nos últimos anos, as percepções das ACS ainda apoiam-se no imaginário popular, e o conceito amplo de saúde mental é pouco compreendido pela categoria.

PALAVRAS-CHAVES Saúde mental; Atenção Primária à Saúde; Agente Comunitário de Saúde.

ABSTRACT This study aimed to identify the perception of the Community Health Agents (ACS) as regards the mental health problems in the community. Intervene with the individuals in psychological distress is a challenge, because madness is marked by negative myths, suggesting to know the conceptions of the professionals involved in the care of these individuals. For the accomplishment of the data collection, it was used a technique of the focus group, followed by content analysis. It was found that, although interventions in the mental health field are being reviewed and performed more widely in past years, the perceptions of ACS still relies on the popular imagination, and the broad concept of mental health is poorly understood by category.

KEYWORDS Mental health; Primary Health Care; Community Health Worker.

1 Universidade de Pernambuco (UPE) -

Recife (PE), Brasil. Instituto de Ensino Superior Santa Cecília (lesc) - Alto do Cruzeiro (AL), Brasil. thamiris.mnc@gmail.com 


\section{Introdução}

O cuidado de base territorial oferecido aos indivíduos em sofrimento psíquico, pouco a pouco, vem construindo um novo espaço social para a 'loucura' e transformando os procedimentos da psiquiatria tradicional (AMARANTE, 2007).

Esse cuidado é motivado pelos ideários da Reforma Psiquiátrica, entre eles, a atual concepção de saúde mental, cujo termo designa uma área extensa e complexa do conhecimento, um campo polissêmico e plural na medida em que diz respeito ao 'estado mental' dos sujeitos e das coletividades. Implica um sentido mais abrangente que engloba a problemática da saúde e da doença, sua ecologia e também traz uma preocupação quanto à utilização e avaliação das instituições, dos profissionais, bem como envolve o estudo das necessidades da comunidade e dos recursos para satisfazê-la (IZAGUIRRE APUD FERNÁNDEZ, 2001; AMARANTE, 2007).

Saúde mental, hoje, tem íntima relação com as práticas de prevenção, promoção e recuperação da saúde, a fim de evitar minimizar ou de ressignificar a vida dos indivíduos em sofrimento psíquico nos seus contextos sociais. É compreendida como um campo de conhecimento e de atuação técnica, engajamento político e compromisso social dos atores envolvidos no âmbito das políticas públicas de saúde (AMARANTE, 2007).

Com base nas atuais concepções e na necessidade de reorientação do modelo de atenção em saúde mental, há evidências de que esse cuidado de base territorial requer a prática de ações intersetoriais e a ampliação das articulações entre os equipamentos da rede de atenção à saúde, sobretudo com a atenção primária, pois este nível tem o potencial de conferir maior resolutividade aos problemas de saúde mental emergentes na comunidade. Além disso, demandas como sinais e sintomas depressivos, transtornos mentais severos e persistentes e transtornos decorrentes do uso prejudicial de álcool ou outras drogas são uma realidade na prática cotidiana desse nível de atenção (SOUZA, 2006; BRASIL, 2009).

Dados do Ministério da Saúde apontam que, em média, 22 a $25 \%$ dos usuários atendidos pelas Equipes de Saúde da Família (EqSF) apresentam transtornos mentais e exigem cuidado integral e continuado em saúde. Além destes, todos os usuários necessitam de atenção em 'saúde mental' (BRASIL, 2009).

Assim, no âmbito territorial, as EqSF - estratégia de operacionalização das diretrizes instituídas em 1994, no Programa de Saúde da Família (PSF) - podem ser vistas como responsáveis por um papel fundamental na construção de um novo modelo de cuidado, uma vez que estão inseridas em um contexto que permite maior aproximação entre usuários, família, comunidade e profissionais. Nessas equipes, destaca-se o papel do Agente Comunitário de Saúde (ACS) - membro de maior proximidade com a realidade local e vinculação com os usuários -, que funciona como elo entre comunitários e EqSF (PEREIRA, 2007; SOUSA, 2007). É um parceiro potencial para as estratégias de cuidado em saúde, em especial, na área de saúde mental, pois reside no território, vivencia situações semelhantes às vividas pelos usuários, identifica os casos e repassa as informações para a equipe. Atua, também, como um tradutor de orientações técnicas, ao favorecer uma linguagem acessível à população (SOUSA, 2007; PEREIRA, 2007).

No entanto, compreende-se que intervir junto a indivíduos em sofrimento psíquico configura-se como um desafio, pois a 'loucura' faz parte de um imaginário construído, marcado por representações sociais, mitos e princípios negativos fortemente instituídos. Tal desafio sugere a importância de se conhecer as concepções dos trabalhadores envolvidos no cuidado aos indivíduos em sofrimento psíquico, como também tem suscitado a necessidade das atividades de apoio matricial junto às EqSF, a consolidação de práticas contínuas de formação e reflexões cotidianas acerca do 
processo de trabalho - a educação permanente -, visto que tais estratégias podem ajudar na desconstrução de mitos populares arraigados nos profissionais e a subsidiar práticas diárias em saúde, com delineamento de uma linha de cuidado de qualidade em saúde mental.

Nessa perspectiva, compreendendo-se que a atenção em saúde mental só será efetiva mediante o seu fortalecimento e sua articulação com a atenção primária, e considerando, principalmente, o papel dos ACS, que podem ser encarados como técnicos de referência no território, o presente estudo tem como objetivo identificar a percepção das ACS atuantes na Estratégia Saúde da Família (ESF) sobre os problemas de saúde mental da comunidade.

\section{Procedimentos metodológicos}

Trata-se de um estudo exploratório, de natureza qualitativa. Foi desenvolvido em um município da Região Metropolitana do Recife/PE, o qual possui 29 bairros distribuídos em uma área aproximada de $52,9 \mathrm{~km}^{2}$, considerada $100 \%$ urbana, ainda que observadas características rurais em algumas regiões, e uma população estimada em 144.466 habitantes (IBGE, 2010).

A história desse território se desenvolveu nos arredores e 'em função' de 02 (dois) dos maiores centros psiquiátricos do Brasil, ambos recentemente desativados e com seus egressos acolhidos pela rede de saúde municipal - dado relevante e que também justifica a escolha do local do estudo.

O município está organizado em 04 (quatro) territórios de saúde e, entre seus dispositivos, dispõe de 42 EqSF a serviço da população, das quais duas, de territórios de saúde diferentes, colaboraram com o presente estudo. Uma das equipes é referência de um bairro situado na região norte do município, com características rurais; enquanto a outra é referência de um bairro localizado na região sul, próximo ao centro urbano e econômico da cidade.
As equipes foram escolhidas a partir das atividades que a pesquisadora, residente do programa de Residência Multiprofissional em Saúde Mental (RMSM), realizou no município, junto à equipe do Núcleo de Apoio à Saúde da Família (Nasf). Foram convidadas a participar da pesquisa todas as ACS integrantes das equipes já referidas, num total de 11 ACS, quantitativo inicialmente organizado em 02 (dois) grupos para coleta de dados Grupo 1 (G.1 - com 7 ACS - urbano) e Grupo 2 (G.2 - com 4 ACS - rural). Durante a coleta das informações, uma das ACS do G.2 encontrava-se de férias, não sendo incorporada à pesquisa. Logo, no grupo G.2, apenas 3 ACS colaboraram com o estudo. Com uma perda na amostra, participou da pesquisa um total de 10 ACS (G.1 - 7 ACS, G.2 - 3 ACS).

Para a coleta dos dados, foi utilizada a técnica do grupo focal, um instrumento que permite reunir grupos pequenos e homogêneos, como parte do público-alvo de investigações, com duração média de 30 minutos a duas horas, a fim de coletar informações sobre determinada temática, a partir do diálogo e do debate entre os indivíduos. Os encontros são mediados por um roteiro e têm coordenação de um moderador, seja para gerar consenso ou para explicitar divergências no grupo estudado (MINAYO, 2010).

A coleta dos dados foi previamente agendada, com datas, horários e locais definidos junto às participantes, mediante suas disponibilidades; foi realizado um encontro com cada grupo de ACS, nos meses de outubro de 2013 (G.1) e janeiro de 2014 (G.2), com duração média de 50 minutos.

A dinâmica foi coordenada pela pesquisadora encarregada de administrar a entrevista e o grupo, enquanto um pesquisador assistente documentou as respostas em formato de relatoria, concomitantemente com a gravação em áudio e vídeo. As discussões foram mediadas com base em perguntas norteadoras, listadas abaixo, a partir das quais foram trabalhados os conceitos de saúde mental e transtorno 
mental; casos de sofrimento psíquico identificados na comunidade e fatores determinantes; e formação profissional. 1. O que você entende como saúde mental? 2. O que é transtorno mental? 3. Quais são os tipos de transtornos mentais que você identifica na comunidade? 4 . O que você acha que são as causas (ou determinantes) desses problemas? 5. Quais são as ações que você desenvolve diante desses problemas, enquanto ACS? 6. Você recebeu alguma capacitação/treinamento/curso de formação para trabalhar com pessoas com transtorno mental?

A participação das ACS deu-se voluntariamente, e as atividades só foram realizadas após a leitura e assinatura do Termo de Consentimento Livre e Esclarecido.

Ao término de cada grupo, foram distribuídas fichas de identificação com informações como: nome, idade, sexo, cor, escolaridade, estado civil, tipo de moradia, renda mensal familiar e tempo que trabalha como ACS, para preenchimento individual, com o objetivo de reconhecer o perfil das ACS envolvidas na pesquisa. As entrevistadas foram codificadas com números de 1 a 10 .

Os dados coletados foram submetidos ao processo de análise de conteúdo, que, segundo Bardin (1977), configura-se como um conjunto de técnicas de análise de comunicação que relaciona as estruturas semânticas (significantes) com as estruturas sociológicas (significados) dos enunciados e articula a superfície das mensagens com os fatores que determinam suas características (psicossociais, contexto cultural, entre outras).

A partir das três etapas cronológicas de Bardin (1977), estruturadas em: 1) pré-análise - fase de organização propriamente dita, com uma análise flutuante; 2) exploração do material - etapa na qual os dados brutos são transformados em unidades temáticas (processo de codificação e categorização); e, 3) tratamento de resultados - inferência e interpretação. Na delimitação do 'corpus do estudo', a fim de facilitar a análise, foram geradas seis unidades temáticas: Conceito de saúde mental; Conceito de transtorno mental; Transtornos identificados na comunidade; Determinantes/causas do transtorno mental; Formação, treinamento, capacitação; Apoio matricial e educação permanente.

O estudo foi submetido ao Comitê de Ética do Complexo Hospitalar HUOC/ Procape, com o Certificado de Apresentação para Apreciação Ética (CAAE) número 20045313.4.0000.5192.

\section{Resultados e discussão}

\section{Quem são e onde trabalham}

Brancas, pardas, morenas, filhas, mães, esposas, solteiras, profissionais, residentes no território onde trabalham, ACS são o elo entre a comunidade e as EqSF, como bem se descrevem e acrescentam: profissionais que prestam cuidados, mas que também precisam ser cuidadas. Mulheres que vivenciam realidades distintas, ainda que tenham o nome do município como algo comum em seus comprovantes de residência. Sobretudo, verdadeiras cidadãs diante de suas comunidades - ACS cidadãs.

Por essas 10 mulheres - nascidas e criadas no município, ou que muito novas chegaram à área do estudo em questão; com idades variando entre 32 (trinta e dois) e 51 (cinquenta e um) anos; na sua maioria, com $2^{\circ}$ grau completo (7); e tempo de serviço como ACS entre 2 e 19 anos - foi constituído o universo trabalhado.

Imersas num território amplo, com características físicas, socioeconômicas e culturais diversas, as entrevistadas descrevem os bairros em evidência no estudo como territórios 'bons' para trabalhar, com comunidades receptivas, porém marcadas pela passividade e 'acomodação' dos 
comunitários, que não se organizam para reivindicar melhorias na infraestrutura das localidades. Principalmente no bairro com características rurais evidentes (G.2), onde a falta de asfalto, de estruturas comerciais e de lazer, transporte precário e descolamento a 'pé' dos comunitários e ACS são uma realidade. "Ela não tem transporte, a gente é precária de transporte; asfalto a gente não tem; a gente não tem um lazer aqui [...]" (ACS 9 - G.2). "[...] reclamam da dificuldade de transporte. Na minha área tem muitos idosos, deficientes, e eles acham muita dificuldade para chegar até a unidade, porque acham longe" (ACS 10 - G.2).

Contudo, os territórios são apresentados como tranquilos, ainda que 'mal' vistos por muitos moradores de bairros ou municípios vizinhos, sobretudo pelo aumento do consumo de substâncias psicoativas, como relata uma ACS do G.1, ou, ainda, como 'um paraíso' para morar, mesmo com os problemas estruturais evidenciados pelas ACS do G.2. "A gente entra aqui e sai a hora que for [...] para a gente não é perigoso, eu não acho" (ACS 3 - G.1). "[...] gosto da tranquilidade. De uns tempos para cá, vem piorando o caso das drogas, mas, no meu ver, é um bairro igual a qualquer um, um bairro mais tranquilo do que muitos [...]" (ACS 4 - G.1). "Temos as nossas dificuldades... Mas, antes de tudo, é uma comunidade boa de morar, é um paraíso [...]” (ACS 10 - G.2).

O perfil das entrevistadas do presente estudo assemelha-se aos apresentados por Sousa (2007), Álvares (2012) e Waidman, Costa e Paiano (2012) em suas pesquisas, nas quais a maioria das participantes era do sexo feminino, o que reafirma a prevalência de mulheres na função de ACS, com idades entre os 25 e 60 anos, com $2^{\circ}$ grau completo e tempo de atuação profissional inferior a 20 anos de prática.

A partir das narrativas individuais das ACS e do conhecimento do contexto no qual estão inseridas é que se passa à análise e discussão das unidades temáticas.

\section{Conceito de saúde mental}

Nos relatos das ACS, pode-se evidenciar o quão difícil é distinguir os termos saúde e doença, parecendo a dificuldade aumentar quando se pretende conceituar saúde mental, uma vez que a definição do termo parece confundir-se ou estar relacionada a quadros de adoecimento, acompanhamento clínico especializado e uso de medicação. "Saúde mental é um distúrbio que o paciente tem com relação ao comportamento normal das pessoas" (ACS 9 - G.2). "Saúde mental, para mim, é o acompanhamento que a gente presta a partir do momento que ele tem aquele diagnóstico, né?” (ACS 8 - G.2). “[...] é está sempre naquele controle, para saber como estão aqueles comunitários, se realmente estão tomando a medicação, se está sendo acompanhado, tanto por psicólogo, psiquiatra" (ACS 4 - G.1). "[...] se encontrar alguém já doente... tomar a medicação corretamente, para ter uma vida normal [...]" (ACS 7 - G.1).

Apenas dois breves discursos fizeram uma associação discreta entre saúde mental e práticas de prevenção e promoção da saúde, tendo ficado evidente, pela maior parte do universo estudado, que saúde mental ainda é compreendida como sinônimo de transtorno mental, termo abordado em seguida: "[...] é quando a gente está trabalhando para que a pessoa não adoeça [...] a gente não trabalha com a medicação, a gente trabalha com a prevenção" (ACS 5 - G.1). "Saúde mental é trabalhar com a orientação e a prevenção" (ACS 2 - G. 1).

Durante muito tempo, tem-se ouvido profissionais referirem 'trabalhar na saúde mental' como uma prática que, num contexto histórico, esteve reduzida ao estudo e ao tratamento das doenças. Todavia, nas últimas décadas, observa-se um processo contínuo de desconstrução e ressignificação dos conceitos e práticas que definem a saúde mental (AMARANTE, 2007; WAIDMAN; COSTA; PAIANO, 2012). 
No entanto, observa-se na literatura (e os dados do presente estudo corroboram) a concepção de que o trabalho para desmistificar conceitos preexistentes, principalmente na atenção primária, junto aos ACS, ainda é discreto, e os eixos norteadores da saúde mental ampliada pouco explorados (WAIDMAN; COSTA; PAIANO, 2012). Ainda que realizem práticas de cuidado de maneira mais abrangente, o conceito de saúde mental, na sua magnitude, parece ser pouco compreendido pelas ACS, sendo por elas associado sempre ao estado/ quadro de adoecimento.

Vale ressaltar que, na busca do referencial teórico para fundamentar o estudo, poucas foram as pesquisas encontradas que traçaram como um dos objetos de estudo, com o público alvo em questão, a compreensão do termo 'saúde mental'. Muitos dos trabalhos localizados exploram apenas a percepção da terminologia transtorno mental, tais como os de Pereira et al. (2007), Sousa (2007) e Costa e Paiano (2012), entre outros.

\section{Conceito de transtorno mental}

Para as participantes, o significado da expressão transtorno mental está relacionado a quadros de adoecimento, ao desequilíbrio, ao que está fora dos padrões. "[...] é quando a pessoa já está doente, né? Aí já está precisando de um atendimento médico, já está precisando de uma atenção maior, ela vai precisar de mais cuidados para que ela não piore" (ACS 5 - G.1). "É o desequilíbrio da mente [...] quando a mente não está funcionando, quando ela não está funcionando dentro da forma correta [...]" (ACS 3 - G.1). "Então, são doenças acometidas no juízo da pessoa [...] e que não segue o parâmetro da sociedade, que não segue o parâmetro, entre aspas, das pessoas comuns" (ACS 9 - G.2).

Os dados corroboram os levantados por Barros, Chagas e Dias (2009) e Álvares (2012), ao verificarem em estudos que a definição de transtorno mental como uma doença de cabeça é significativamente comum entre os ACS, cuja identificação dá-se facilmente em função de características comportamentais destoantes do consenso construído pelo coletivo.

Os sujeitos estudados apresentam conceitos que remetem a indivíduos em situação que demanda cuidados, mas os relatos demonstram insegurança para definir a expressão transtorno mental. Essa dificuldade para estruturar a definição do termo pode ser um reflexo do termo transtorno, ainda bastante utilizado, e fruto de um imaginário social construído, o qual remete a transtornado, o mesmo que possesso, (AMARANTE, 2007; ÁlVARES, 2012).

Tais colocações confirmam a importância de falar, compreender, cuidar de sujeitos e utilizar, cotidianamente, o termo sofrimento psíquico ou mental, seja pelos profissionais e pelas instituições de saúde ou na própria comunidade. A ideia de sofrimento nos remete a pensar em um indivíduo que sofre, nas experiências por ele vividas, nos contextos em seu entorno e nos papeis sociais que desempenha. Logo, trabalhar com essa concepção, bem como difundi-la na sociedade, pode possibilitar a desconstrução de mitos enraizados na cultura popular e libertar o sujeito em sofrimento psíquico das representações reducionistas de um diagnóstico: de um ser sadio ou doente, normal ou anormal, o diferente.

\section{Transtornos mentais identificados na comunidade}

Ao serem questionadas sobre os transtornos mentais que identificam nas atividades cotidianas, as ACS listam uma variedade de diagnósticos presentes na CID-10, ainda que refiram não conhecê-los de fato, demonstrando nos relatos compreender e acolher o sujeito pelos sinais e sintomas apresentados. "Fobia tem muito [...] drogas, síndrome do pânico... o transtorno bipolar, autismo" (ACS 7 - G.1). "Eu vejo muita ansiedade, agressividade, depressão tem muita [...]” (ACS 5 -G.1). 
"Esquizofrenia, depressão, ansiedade, síndrome do pânico" (ACS 8 - G. 2). "O que eu vejo aqui é muita depressão" (ACS 9 - G.2). "[...] falta de sono, que escuta vozes, não querem comer, nem dormir, nem tomar banho. Muitos ficam quieto, calado, no cantinho" (ACS 10 - G.2).

Apontam uma maior frequência de casos de depressão e esquizofrenia identificados, com ênfase para depressão. "Acho que depressão, depressão tem demais [...]” (ACS 3 G.1). "O que eu vejo aqui é depressão e muita, e esquizofrenia” (ACS 8 - G.2).

Os discursos assemelham-se aos observados por Sousa (2007) e Álvares (2012) em estudos com ACS, nos quais as ACS mencionaram diagnósticos, tais como os supracitados, de maneira não especificada; e reforçam a familiaridade das ACS com transtornos psicóticos (esquizofrenia) e depressivos, principalmente com a depressão.

Estudo da Organização Mundial de Saúde (OMS), conduzido no Rio de Janeiro, apontou uma prevalência de $29,5 \%$ de diagnósticos de transtornos depressivos na atenção primária, sem contar no contato cotidiano das ACS com demandas caracterizadas por sintomas ansiosos, depressivos e somatoformes (VALENTINI ET AL., 2004). Os dados ajudam a justificar os relatos das agentes de saúde quando declaram se deparar mais frequentemente com tal tipo de sofrimento no exercício de sua profissão.

Verificou-se ainda na análise dessa unidade temática que as agentes comunitárias não apontaram espontaneamente, durante a discussão, o uso prejudicial de álcool e outras drogas como um transtorno mental. Após serem questionadas, lançaram mão de alguns discursos que, embora apontem o consumo dessas substâncias pelos comunitários, não definem seguramente a dependência química como uma situação de sofrimento psíquico. "Tem também o transtorno pelo álcool e outras drogas" (ACS 7 - G.1). "[...] acho que é até um tipo de transtorno a dependência" (ACS 5 - G.1). "[...] eu acho, pelo menos nessa área da gente, acho que o maior problema de saúde mental é o consumo de droga" (ACS 3 - G.1)

Por fim, foram observadas nas falas dúvidas quanto a essa questão, principalmente pelos sujeitos do G.2, e até mesmo na política de saúde, na qual o uso prejudicial de álcool e outras drogas está inserido. "Saúde do homem, já que a maioria dos alcoolistas são homens" (ACS 8 - G.2).

Observa-se, também, que há raras referências aos transtornos decorrentes do uso prejudicial de álcool e outras drogas, bem como a compreensão do mesmo como uma questão de saúde mental, sobretudo pela utilização do álcool, cujo consumo é socialmente aceito e pouco chama atenção das ACS (SOUSA, 2007).

\section{Determinantes/causas dos trans- tornos mentais identificados na comunidade}

Para as ACS, as causas dos transtornos mentais parecem estar relacionadas, na sua maioria, a fatores externos. Os contextos sociais nos quais o sujeito está inserido, as relações estabelecidas e os eventos ocasionais do ciclo vital são citados como os principais fatores determinantes do sofrimento psíquico.

Muita ociosidade. Jovens que não trabalham, não estudam, não querem nada, passam o dia sem fazer nada e terminam entrando nas drogas. Aí gera um problema familiar, a mãe adoece, entra em depressão, e aí começam os transtornos, gera um desequilíbrio na família toda, né? (ACS 1 - G.1).

"É o nível de estresse muito alto, desemprego, um falecimento, perda de um familiar, é o estresse do dia a dia, é algum problema que ele não sabe conduzir diante da vida" (ACS 8 - G.2). 
Diversos fatores foram apontados pelas ACS, condizendo com a gênese multifatorial dos transtornos mentais apresentada pela OMS (2001), que pontua como sendo diversos os fatores que determinam a prevalência, o início e a evolução dos transtornos mentais. Segundo a OMS, fatores sociais e econômicos, demográficos (sexo e idade), ameaças graves, como conflitos e desastres, a presença de doença física grave e o ambiente familiar estão entre estes fatores determinantes do sofrimento psíquico.

Assim como pontuado por Sousa (2007), para as ACS do presente estudo, o sofrimento mental decorre de vários excessos, como problemas, preocupações, estresses da vida cotidiana e das dificuldades de cada um para superar os problemas vividos.

Os dados ainda corroboram com Barros, Chagas e Dias (2009), que referem também estarem implicados na origem dos transtornos mentais os eventos de vida que desestabilizam o estado emocional do indivíduo, como a perda de familiares, do emprego ou a ociosidade. Os autores observaram que as ACS sinalizam, com destaque, o desemprego e as dificuldades financeiras como fatores determinantes para o desequilíbrio da saúde mental.

Não menos importante, mas pouco pontuado pelas ACS do presente estudo, foram os fatores genéticos, hereditários, como determinantes no processo de sofrimento psíquico, tendo sido necessário, junto a um dos grupos, mencionar a temática, para, assim, vir à tona a discussão. "Algumas são da genética, mas algumas vêm pelo ambiente, pelo contexto" (ACS 1 - G.1). "Surgem por questões externas e também familiares, hereditário também existe isso. Não só as causas externas do dia a dia" (ACS 9 - G. 2).

O fato apontado pode ser justificável, uma vez que as dificuldades para identificar as alterações genéticas e fisiológicas determinantes dos transtornos mentais ainda são uma realidade, pois, diferentemente das doenças clínicas, cujas causas e efeitos são facilmente comprovados, os transtornos mentais têm sua organicidade ancorada na incerteza - na chamada etiologia não definida (SALUM JÚNIOR, 2012). Os fatores genéticos são, muitas vezes, esquecidos ou não mencionados, assim como o sofrimento psíquico, atrelado à subjetividade do sujeito, bem como aos fatores do ambiente no qual está inserido.

É preciso atentar, também, para o fato de que o transtorno mental, quando entendido como hereditário, assume uma roupagem 'fatalista', já que não se pode, segundo essa perspectiva, interferir na sua gênese; e o indivíduo, no lendário popular, torna-se estigmatizado, predestinado à dependência do meio, incapaz de desempenhar adequadamente os papéis ocupacionais e sociais exigidos pela coletividade. Essa associação pode, também, justificar o fato de as condições genéticas não terem sido muito citadas como fator determinante do sofrimento psíquico (BARROS; CHAGAS; DIAS, 2009).

Assim, torna-se evidente que as ACS entendem como determinantes da saúde mental macrofatores, associados não só ao setor saúde, imediatamente perceptíveis, mas a fatores externos a este, como o trabalho, o desempenho de papéis e as redes de apoio social (BARROS; CHAGAS; DIAS, 2009).

\section{Formação, treinamento, capacitação}

No material compilado, observou-se que as ACS relatam poucos ou nenhum processo de formação, capacitação, treinamento ou preparação para que possam intervir junto às demandas de saúde mental da comunidade. Ao mesmo tempo, referem ter interesse em receber formação e reconhecem a necessidade dessas ações para compreensão da complexidade que envolve o sofrimento psíquico e a consequente melhoria de seus processos de trabalho. "Vocês receberam algum treinamento? (Pesquisadora) Naaaaaaaão! [um coro]" (G.1). "A gente não tem capacitação desde a época de [...] há mais de 10 anos" (ACS 5 - G.1). "A gente já teve, no 
iniciozinho, sobre saúde mental, mas sobre medicação, não" (ACS - G.1). "Eu queria muito. Eu acho que o que a gente tem mais dificuldade em saúde é saúde mental" (ACS 6 - G.1). "Rapaz, eu não me lembro, não. Até porque faz muito tempo que a gente não teve uma capacitação. Está voltando a ter agora, está voltando a se reciclar agora" (ACS 9 - G. 2). "Sim, a gente precisa muito desse curso de saúde mental” (ACS 10 - G.2).

Os dados do presente estudo não diferem dos encontrados por Vecchia e Martins (2009) e Álvares (2012), nos quais as ACS apontam a inexistência de processos de capacitação nas localidades pesquisadas ou fragilidades quando os mesmos acontecem, sobretudo, no que concerne às metodologias utilizadas, que, na maioria das vezes, não dialogam com a realidade por elas vivenciada; bem como a importância e o interesse em realizá-las. Essas evidências vão de encontro às inúmeras mudanças que operam no campo das políticas públicas, como na Reforma Psiquiátrica, que exige qualificação dos recursos humanos, principalmente da atenção primária, diante do modelo de cuidado de base territorial preconizado.

Damos destaque para a fala seguinte, que problematiza a questão das metodologias utilizadas durante os processos formadores.

Se conseguirem alguma capacitação em saúde mental [...] Seria bom e interessante que fosse assim, dinâmica, ter um dinamismo, uma dinâmica de trabalho diferente, uma capacitação diferente. Porque, geralmente, é o instrutor na frente e o agente de saúde atrás, e ele só vomita, vomita, vomita... que fosse uma coisa envolvente, que envolvesse mesmo e desse gosto de participar. Porque a gente só fica lá a manhã toda só sentada, e 'priu', aí sai. Muitas vezes, acrescenta coisas que a gente sabe, mas, muitas vezes, é só um repasse. Que fosse uma capacitação como oficina, oficina, entendesse? (ACS 9 - G.2).
No relato supracitado, pode-se evidenciar que é uma realidade, durante as capacitações e demais espaços de formação das ACS, a lógica da educação bancária, compreendida por Paulo Freire (1987) como uma relação fundamentalmente narradora entre educador e educando. Metodologia na qual a educação se torna um ato de depositar conteúdos, com o educador na função de depositante e os educandos como os depositários.

Concomitantemente, os resultados sugerem reflexões acerca da formação em saúde mental ofertada aos agentes comunitários e de como ela vem sendo por eles compreendida. Desde o ano de 2002, o Ministério da Saúde desenvolve o Programa Permanente de Formação de Recursos Humanos para a Reforma Psiquiátrica, que incentiva, apoia e financia a implantação de núcleos de formação em saúde mental para a rede pública, com alguns cursos somente para ACS. Programas esses desenvolvidos através de convênios com instituições formadoras (especialmente universidades federais), municípios e estados, e que contabilizam inúmeras capacitações para integrar saúde da família e saúde mental numa única rede de cuidados aos usuários de todo o Sistema Único de Saúde (BRASIL, 2007).

Cabe pontuar que, embora as ACS do estudo não tenham realizado curso técnico para exercerem essa função, o município no qual atuam possui um vasto histórico de ações voltadas para formação profissional, sobretudo com ênfase na educação permanente como proposta formadora. Ressaltase, ainda, que no período da coleta de dados da pesquisa apenas um dos grupos das ACS havia iniciado o projeto Caminhos do Cuidado, desenvolvido recentemente pelo Ministério da Saúde, com a meta de oferecer formação em saúde mental, crack e outras drogas para ACS e Auxiliares e Técnicos de Enfermagem. O projeto supracitado não foi referido pelas agentes de saúde durante a coleta dos dados. 


\section{Apoio matricial e educação permanente}

Durante a coleta de dados, chamou atenção nos discursos o fato de os sujeitos pesquisados apontarem que adquirem conhecimento do processo de trabalho no dia a dia e que têm suporte de alguns profissionais como algo presente nas suas atividades cotidianas. No entanto, as nomenclaturas das estratégias utilizadas como sendo práticas de educação permanente e apoio matricial não foram referidas durante a pesquisa, e a compreensão de que tais atividades fazem parte de um espaço contínuo de formação e qualificação profissional não parece clara ou do conhecimento das ACS. "A gente pega a manha no dia a dia, mas a gente precisa de orientação" (ACS 3 - G.1).

E o psicólogo daqui, não é um curso que ele dá. Ele dá uma pincelada, para ser mais fácil, para a gente identificar alguma necessidade que aquele paciente tenha de procurar um profissional. Ele faz em cada reunião, fala sobre o que é esquizofrenia, dá uma pincelada do que seja esquizofrenia, o estresse, o que leva, entendeu? Ele dá uma pincelada. (ACS 9 - G.2).

A partir dos discursos analisados e do levantamento do referencial teórico para fundamentar o estudo em questão, constata-se a escassez de pesquisas que abordem diretamente as temáticas do apoio matricial e da educação permanente com os ACS, a fim de identificar a real compreensão das ACS quanto às metodologias referidas. Foi possível localizar estudos, como o de Cunha e Campos (2011), entre outros, que apresentam os resultados de estratégias de apoio matricial de um modo geral, junto aos agentes de saúde (com intervenções e avaliações em um espaço de tempo delimitado), na maioria, bem sucedidas e operacionalizadas por equipes ligadas ao campo da pesquisa como centros universitários, programas de residências em saúde, entre outros.
Estudos de equipes matriciadoras permanentes que avaliem impactos do apoio matricial no cuidado em saúde e a compreensão da estratégia pelas ACS, desde o significado da expressão à importância no processo de trabalho, não foram identificados até a estruturação final do artigo.

Os dados chamam a atenção e fazem recordar o conteúdo referido pelo Ministério da Saúde (2007) no 'Relatório de Gestão 2003-2006' (BRASIL, 2007). No documento, a implantação, expansão e qualificação do apoio matricial (conceituado como uma metodologia de trabalho que visa a assegurar, além da retaguarda especializada, no nível assistencial e técnico-pedagógico, um espaço no qual ocorra intercâmbio sistemático de conhecimento entre equipes de referência - profissionais da atenção primária e os apoiadores) foram apresentadas como um dos principais desafios para a gestão da política de saúde mental (CAMPOS; DOMITTI, 2007). Também foi apontada a necessidade do fortalecimento de uma política efetiva de formação continuada, compreendida como o processo educativo que coloca o cotidiano do trabalho ou da formação em saúde em análise - a educação permanente -, como uma das principais prioridades para consolidação do cuidado integral do sujeito nos anos seguintes ao relatório. Continuam esses ainda sendo os desafios para a expansão das ações de saúde mental na atenção primária?

A ausência da denominação clara e espontânea dessas ações, pelas participantes da pesquisa, pode permitir, ainda, alguns questionamentos para estudos futuros, sobretudo pela compreensão de que tais metodologias podem ajudar na desconstrução de pré-conceitos populares relacionados ao sofrimento psíquico, e subsidiar práticas diárias em saúde, com delineamento de uma linha de cuidado de qualidade em saúde mental. 


\section{Considerações finais}

Perfazer e tentar depreender os caminhos que levam à prática das ACS revelou que as intervenções no campo da saúde mental estão sendo reformuladas e realizadas de maneira mais abrangente ao longo dos últimos anos. No entanto, as percepções da categoria ainda estão pautadas no imaginário popular, e o conceito amplo de saúde mental pouco compreendido e aplicado nas práticas cotidianas dessas profissionais.

Durante a análise dos dados e a identificação do perfil das ACS, chamaram atenção as variáveis grau de escolaridade e tempo de experiência profissional. Ainda que a maioria apresente $2^{\circ}$ grau completo e mais de 10 anos de exercício da função, esses elementos não se mostraram determinantes para justificar a aquisição de percepções mais amplas da saúde mental e do sofrimento psíquico, como também uma fundamentação das atividades profissionais sem a exigência frequente de espaços de formação para a construção de conhecimento técnico-científico.

É bem verdade que, para muitos, o conhecimento gera a necessidade de mais conhecimento, e capacitações com fundamentação técnica acabam por se tornar uma exigência pessoal e profissional constante dos atores envolvidos no cuidado em saúde. Essa cobrança parece se destacar entre os agentes comunitários, cuja identidade profissional é marcada pelos valores e pela cultura dos territórios nos quais estão inseridos, e o saber empírico é a principal base conceitual do processo de trabalho. Essa dicotomia gera conflitos e contradições entre manter a essência da categoria, com base nos conhecimentos populares, ou instrumentalizar científica e academicamente esses profissionais. Fato é a importância de somar esses conhecimentos, populares e científicos, para a efetivação das políticas de saúde mental, principalmente na atenção primária.

Os dados do estudo apontam que, para além de instituir uma política de saúde mental que garanta os direitos dos sujeitos em sofrimento psíquico, por anos à margem da sociedade, faz-se necessário formar, qualificar e apoiar os profissionais envolvidos no processo de cuidado, principalmente considerando as suas percepções oriundas de um processo cultural, cuja lógica manicomial e asilar era a única estratégia de atenção à saúde, para, a partir de então, trabalhar na perspectiva da desconstrução de conceitos, mitos e preconceitos, que até hoje permeiam o imaginário popular e comprometem o cuidado do sujeito em sofrimento psíquico.

A análise dos resultados obtidos no estudo respondeu às questões iniciais, tidas como norteadoras da pesquisa, e também apontou para reflexões importantes. Mas a pesquisa é, sim, o ponto de partida para novas investigações, ao apontar reflexões importantes sobre a trajetória local da formação dos profissionais da atenção primária com relação à saúde mental e sobre as possíveis ações a partir das estratégias de educação permanente e apoio matricial. 


\section{Referências}

ÁLVARES, J. C. Percepção dos agentes comunitários de saúde sobre as práticas de saúde mental na unidade básica de saúde da família do Paranoá no Distrito Federal. 2012. Dissertação (Mestrado em Ciências da Saúde) - Faculdade de Ciências da Saúde da Universidade de Brasília, Brasília, 2012. Disponível em: < http:// repositorio.unb.br/bitstream/10482/10726/1/2012 JulianaCardoso\%C3\%81lvares.pdf > . Acesso em: 15 mar. 2013.

AMARANTE, P. Saúde mental e atenção psicossocial. Rio de Janeiro: Editora FIOCRUZ, 2007.

BARDIN, L. Análise de conteúdo. Portugal: Edições 70, 1977.

BARROS, M. M. M. A.; CHAGAS, M. I. O.; DIAS, M. S A. Saberes e práticas do agente comunitário de saúde no universo do transtorno mental. Ciência e Saúde Coletiva, Rio de Janeiro, v. 14, n. 1, 2009, p. 227-232. Disponível em: < http://www.redalyc.org/articulo. oa?id=63014124>. Acesso em: 15 mar. 2014 .

BRASIL. Ministério da Saúde. Secretaria de Atenção à Saúde/DAPE. Saúde Mental no SUS: acesso ao tratamento e mudança do modelo de atenção. Relatório de Gestão 2003-2006. Ministério da Saúde: Brasília, janeiro de 2007, 85p. Disponível em: <http://bvsms.saude. gov.br/bvs/publicacoes/relatorio_gestao_saude_mental_2003-2006.pdf>. Acesso em: 20 mar. 2014.

Ministério da Saúde. Secretaria de Atenção à Saúde. Departamento de Atenção Básica. Diretrizes do $N A S F$ - Núcleo de Apoio à Saúde da Família. Brasília, 2009. Disponível em: <http://bvsms.saude.gov.br/bvs/ publicacoes/caderno_atencao_basica_diretrizes_nasf. pdf >. Acesso em: 05 mar. 2014.

CAMPOS, G. W. S.; DOMITTI, A. C. Apoio matricial e equipe de referência: uma metodologia para gestão do trabalho interdisciplinar em saúde. Cadernos de Saúde Pública, Rio de Janeiro, v. 23, n. 2, 2007, p. 399407. Disponível em: <http://www.scielo.br/scielo.
php?pid=S0102-311X2007000200016\&script=sci_arttext>. Acesso em: 10 mar. 2014.

CUNHA, G. T.; CAMPOS, G. W. S. Apoio Matricial e Atenção Primária em Saúde. Saúde e Sociedade, São Paulo, v. 20, n. 4, 2011, p. 961-970. Disponível em: < http://www.scielo.br/scielo.php?script=sci_arttext\&pid =S0104-12902011000400013 >. Acesso em: 20 mar. 2014.

FERNÁNDEZ, M. R. A prática da psicanálise lacaniana em centros de saúde: psicanálise e saúde pública. Dissertação (Mestrado em Saúde Pública) - Escola Nacional de Saúde Pública da Fundação Oswaldo Cruz, Rio de Janeiro, 2001. Disponível em: <http://portalteses.icict.fiocruz.br/pdf/FIOCRUZ/2001/fernandezmrm/capa.pdf>. Acesso em: 05 mar. 2014.

FREIRE, P. Pedagogia do oprimido. 17 ed. Rio de Janeiro: Paz e Terra, 1987. Disponível em: <http://www. letras.ufmg.br/espanhol/pdf\%5Cpedagogia_do_oprimido.pdf>. Acesso em: 15 maio 2014.

\section{INSTITUTO BRASILEIRO DE GEOGRAFIA E} ESTATÍSTICA (IBEGE). Cidades. Disponível em: < http://www.ibge.gov.br/cidadesat/topwindow.htm?1> Acesso em: 07 mar. 2013

MINAYO, M. C. S. Técnicas de pesquisa. In.: O desafio do conhecimento: pesquisa qualitativa em saúde. 12 ed. São Paulo: HUCITEC, 2010.

ORGANIZAÇÃO MUNDIAL DE SAÚDE (OMS). Saúde Mental: nova concepção, nova esperança. Relatório sobre a Saúde no Mundo, Genebra, 2001. Disponível em: < http://www.abebe.org.br/wp-content/uploads/oms2001.pdf >. Acesso em: 06 mar. 2014.

PEREIRA, M. A. O.; BARBIERI, L.; PAULA, V. P.; FRANCO, M. S. P. Saúde mental no Programa de Saúde da Família: conceitos dos agentes comunitários sobre o transtorno mental. Rev Esc Enferm USP, São Paulo, v. 41, n. 4, p. 567-572, 2007. Disponível em: < http://www.scielo.br/ pdf/reeusp/v4ln4/04.pdf >. Acesso em: 15 mar. 2013. 
SALUM JÚNIOR, G. A. Transtornos mentais comuns na infância: estudo de mecanismos genéticos e neuropsicológicos. 2012. Tese (Doutorado em Ciências Médicas-Psiquiatria) - Universidade Federal do Rio Grande do Sul, Porto Alegre, 2012. Disponível em: < http://www.lume.ufrgs.br/bitstream/handle/10183/61914/000867722.pdf?sequence=1>. Acesso em: 17 mar. 2014.

\section{SOUSA, G. C. O Agente Comunitário de Saúde e Saúde} Mental: percepções e ações na atenção às pessoas em sofrimento mental. 2007. 106f. Dissertação (Mestrado de Enfermagem em Saúde Coletiva) - Escola de Enfermagem da Universidade de São Paulo, São Paulo, 2007. Disponível em: <www.teses.usp.br/teses/disponiveis/7/7137/.../Gianne_Carvalho.pdf $>$. Acesso em: 15 mar. 2013.

SOUZA, A. C. Ampliando o campo da atenção psicossocial: a articulação dos centros de atenção psicossocial com a saúde da família [internet]. Esc Anna Nery Rev Enferm, v. 10, n. 4, dez. 2006, p. 703-710. Disponível em: <http://www.scielo.br/pdf/ean/v10n4/v10n4a12>. Acesso em: 05 mar. 2014.
VALENTINI, W. et al. Treinamento de clínicos para o diagnóstico e tratamento da depressão. Rev. Saúde Públ., São Paulo, v. 38, n. 4, 2004, p. 522-528. Disponível em: <http://www.scielosp.org/pdf/rsp/v38n4/21081. pdf $>$. Acesso em: 05 mar. 2014.

VECCHIA, M. D.; MARTINS, S. T. F. Concepções dos cuidados em saúde mental por uma equipe de saúde da família, em perspectiva histórico-cultural. Ciência e Saúde Coletiva, São Paulo, v. 14, n. 1, 2009, p. 183-193. Disponível em: < http:// www.scielo.br/scielo.php?script=sci_arttext\&pid =S1413-81232009000100024>. Acesso em: 20 mar. 2014.

WAIDMAN, M. A. P.; COSTA, B.; PAIANO, M.

Percepção e atuação do agente comunitário de saúde em saúde mental. Rev Esc Enferm USP, São Paulo, v. 46, n. 5, 2012, p. 1170-1177. Disponível em: <http://www.scielo.br/ pdf/reeusp/v46n5/19.pdf>. Acesso em: 10 fev. 2014.

Recebido para publicação em julho de 2014

Versão final em janeiro de 2015

Conflito de interesse: inexistente

Suporte financeiro: não houve 